\title{
Do Identity Frames Impact Support for Multiracial Candidates? The Case of Kamala Harris
}

\author{
Katherine Clayton ${ }^{1, \star}$ (D), Charles Crabtree ${ }^{2}$ (iD) and Yusaku Horiuchi ${ }^{2}$ (D) \\ ${ }^{1}$ Department of Political Science, Stanford University, 616 Jane Stanford Way, 100 Encina Hall West, \\ Stanford, CA 94305, USA and ${ }^{2}$ Department of Government, Dartmouth College, 3 Tuck Mall, \\ 211 Silsby Hall, Hanover, NH 03755, USA \\ *Corresponding author. Email: kpc14@stanford.edu
}

\begin{abstract}
The number of multiracial candidates seeking office is growing in an increasingly diverse America. This raises questions about how the media frame candidates with potentially complex racial backgrounds and how voters respond to these frames. We investigate the impact of media frames that emphasize race and gender attributes using survey experiments on Kamala Harristhe first Black woman and first Asian woman vice president. Our findings are mixed. In a survey experiment conducted after her nomination, headlines emphasizing different elements of Harris's race or gender had no impact on public attitudes. In an experiment conducted after Harris was inaugurated, however, headlines that cued her gender only or both her gender and her Black racial background boosted popular support. Taken together, these findings suggest that some types of identity-based cues may matter, but the effects are sensitive to experimental settings and contexts.
\end{abstract}

Keywords: identity politics; media frames; multiracial; race; ethnicity; gender; Kamala Harris

\section{Introduction}

On January 20, 2021, Kamala Harris was sworn in as vice president of the United States. Her inauguration was historic because Harris, the daughter of immigrants from Jamaica and India, is the first woman, first Black person, and first Asian person in American history to hold this position. Since Joe Biden announced that he had picked Harris as his running mate, one of the most striking characteristics of news coverage about her is that the media have framed her identity in many different ways. There have been headlines from major news outlets announcing, "Kamala

\footnotetext{
We thank Ray Block, Nadia Brown, John Carey, Christian Davenport, Lauren Davenport, Darren Davis, E.J. Graff, Vincent Hutchings, Okiyoshi Takeda, and Marc Tesler for their helpful comments. - OThis article has earned badges for transparent research practices: Open Data and Open Materials. For details see the Data Availability Statement.

(C) The Author(s), 2022. Published by Cambridge University Press on behalf of The Experimental Research Section of the American Political Science Association. This is an Open Access article, distributed under the terms of the Creative Commons Attribution licence (http://creativecommons.org/licenses/by/4.0/), which permits unrestricted re-use, distribution and reproduction in any medium, provided the original article is properly cited.
} 
Harris officially becomes the first Black woman to be a major party's vice presidential nominee" (Reston and Collinson 2020), "Kamala Harris and the rise of Indianorigin politicians in the West" (Tharoor 2020), and "Kamala Harris makes history as first female vice president" (Camera 2021), to name a few. ${ }^{1}$

Given the large body of research documenting the impact of identity frames on public opinion and political behavior (e.g., Winter 2008), we might believe that journalists' choices to highlight certain aspects of a multiracial politician's demographic background over others - when there is more than one element to "choose" fromcould impact voters' political attitudes. Despite surges in the number of multiracial candidates seeking office in the United States (Hardy-Fanta et al. 2016) and increased focus on the politics of the growing population of multiracial voters (e.g., Davenport 2018; Davenport, Franco, and Iyengar 2022), however, only a small number of existing studies have focused specifically on how different identity-based cues influence voters' attitudes toward multiracial political candidates (e.g., Adida, Davenport, and McClendon 2016; Andersen and Junn 2010; Lemi 2021).

In this article, we examine how different identity-based cues influence voters' attitudes toward Harris. We administered two survey experiments at critical points in her career - one just after Harris became Biden's running mate and the other after she was inaugurated as vice president. A notable feature of both experiments lies in their pronounced ecological validity; we used an actual high-profile multiracial politician rather than hypothetical ones in hypothetical settings (e.g., Lemi 2021) during a time in which the media were using a variety of different frames in their coverage of Harris. Considering the salience of Harris's historic vice presidency and the potentially far-reaching effects of media coverage about her on public opinion, we take an approach different from the existing literature. Specifically, we examine reactions to identity-based cues among two large, national samples of approximately 7,000 Americans instead of focusing on coethnic voters only (e.g., Adida, Davenport, and McClendon 2016) or statewide samples (e.g., Andersen and Junn 2010; Harris-Lacewell and Junn 2007). Unlike previous research on public support for multiracial politicians, we also examine how the intersection of race and gender shape public opinion, rather than the effect of race only.

Our findings are mixed. In the post-nomination study, headlines highlighting Harris's race or gender had no impact on public attitudes. In the post-inauguration study, however, a headline that framed Harris as a Black woman or just as a woman consistently boosted popular support. These cues also increased perceptions that her vice presidency would advance gender equality and racial justice in the United States. By contrast, cues that emphasized Harris's Asian or multiracial background in the context of her inauguration, or highlighted her race without mentioning her gender, had no consistent effects. Taken together, these findings suggest that some types of identity-based cues may matter, but that their effectiveness is likely to be conditional on experimental settings and contexts. This underscores the need for more research about the conditions under which identity frames shape public attitudes toward multiracial and intersectional political candidates.

\footnotetext{
${ }^{1}$ Harris herself has reflected on both her Indian and her Black heritage, noting that she is the proud daughter of a Hindu immigrant single mother who immersed her daughters in Black culture. However, she prefers to call herself simply "an American" (Harris 2019).
} 


\section{Framing identity}

There is a broad political science literature on the effects of messaging about race, ethnicity, and gender on public opinion and political behavior. ${ }^{2}$ Some of this research focuses on framing, which occurs when a source motivates a particular way of thinking about an evaluative target (e.g., a social issue, a political candidate, etc.), thereby swaying public opinion (e.g., Chong and Druckman 2007; Nelson, Oxley, and Clawson 1997). Framing theory suggests that the identity-based cues that the media employ in describing political figures could influence public attitudes. ${ }^{3}$ The impact of identity-based cues might be particularly high in biracial election contests or when female candidates are running, as the media tend to place particular emphasis on candidates' demographics in these contexts (Caliendo and McIlwain 2006; Kahn 1994; Ward 2016). The consequences of heightened media attention to race and gender in the political arena, however, are mixed. On the one hand, race and gender frames can harm minority and/or women candidates by activating prejudice and stereotyped thinking (Larson 2006; Reeves 1997; Terkildsen and Schnell 1997). On the other hand, some research suggests that these candidates' ability to attract positive media attention based on their identity may be improving as a more diverse group of individuals seeks office (Gershon 2013) or as norms of egalitarianism become increasingly entrenched (e.g., Huddy and Feldman 2009).

The choice that journalists face about how to frame multiracial candidates is complicated because the media have a broader and more complex set of frames that they can use. Some scholarly research has examined how these frames affect public support for multiracial political figures, with mixed results. In a hypothetical setting, Lemi (2021) uses a conjoint experiment to show that multiracial candidates attract support from a broad group of voters, but that they face disadvantages when appealing to individuals who share just one of their races and have strong racial identities. Other studies manipulate racial and ethnic cues in the context of real political candidates, as in our study, and draw alternative conclusions. In a survey experiment conducted in Illinois, Andersen and Junn (2010) varied the degree and content of Barack Obama's racialization as a Black candidate in the 2004 U.S. Senate race. They find that when Obama was portrayed as white, white Democrats became more positive in their assessments of his ability, but that the racialization of the frame had no influence on how white Republicans evaluated Obama. ${ }^{4}$ In another experiment that employs a similar methodology to ours, Adida, Davenport, and McClendon (2016) manipulated ethnic cues in a news article about Charles Rangel, a Black and Latino Congressman from New York, and evaluated the effects of the cues on Black and Latino voters' political attitudes. They find that Black voters respond positively to coethnic cues, while there are no measurable effects among Latino voters.

\footnotetext{
${ }^{2}$ Much of this literature focuses on racial priming, which occurs when cues in the information environment (often delivered via references to racialized policies, language, or imagery) activate or deactivate identity-based stereotypes and predispositions, thereby shaping public opinion about racial groups, individuals, and policies indirectly (Mendelberg 2001; see Hutchings and Jardina 2009 for a review). In contrast, we are interested in identity-based framing.

${ }^{3}$ We use the terms "frames" and "cues" interchangeably.

${ }^{4}$ See also Harris-Lacewell and Junn (2007) for a related study that considers the influence of both racial and religious cues on Obama's 2004 Senate race in Illinois.
} 
The literature on the effects of framing on attitudes toward multiracial political candidates remains incomplete for several reasons. First, to our knowledge, no studies have specifically examined attitudes toward multiracial women candidates, whose gender presents yet another layer of identity-based framing that the media can choose to highlight. Indeed, understanding the independent and joint effects of race and gender on candidate evaluations is an important contribution to a wide literature on intersectional identities in politics in general (e.g., Hughes 2011), and a growing literature on the politics of Black women in particular (Gay and Tate 1998; Philpot and Walton 2007).

Second, given the high salience of Harris's vice presidency and its potential implications for American public opinion, we examine the impact of identity-based cues among two national samples of Americans instead of focusing on coethnic voters only or voters in a single state. This permits us to consider how the effects of identity frames could impact voting behavior at the national level, which is increasingly important as the diversity of individuals seeking political office and the number of citizens identifying with multiple races grows (Lee and Bean 2004).

Finally, we run two experiments to understand how identity frames impact public opinion across survey samples, time, and information contexts, allowing us to consider the scope conditions of the effect of identity frames on public opinion. While we can only speculate about why the results we observe differ across our two studies, these differences productively highlight the fact that the effects of identity-based cues may be sensitive to experimental settings and contexts.

\section{Survey experiments}

To examine how race and gender cues affect attitudes toward multiracial candidates, we conducted two preregistered online survey experiments with national samples of Americans. The first (hereafter, post-nomination study) was conducted shortly after Biden announced that he had selected Harris as his running mate in the 2020 presidential election, and the second (post-inauguration study) was conducted shortly after Biden and Harris were inaugurated. ${ }^{5}$ We describe the survey design and results of each study below and consider how they speak to one another in the next section (Section 4). See Sections A to C in the Supplementary Materials for additional information about our surveys, including our analyses of treatment effect heterogeneity across demographic and attitudinal subgroups in our sample.

\section{Post-nomination study}

We fielded the post-nomination study on August 18-19, 2020, and collected a quota-based national sample of 3,053 voters in the United States using Lucid Theorem. We first stratified study participants into sixteen subgroups by gender, race/ethnicity, and partisanship. We then randomly assigned participants to one of four treatment conditions or a control condition within each stratum. In the

\footnotetext{
${ }^{5}$ We preregistered each study at the Open Science Framework before collecting our data (see https://osf. io/vxuty and https://osf.io/6r2gc). Both studies were approved by the Committee for the Protection of Human Subjects at Dartmouth College (ID: STUDY00032142, MOD00010609).
} 


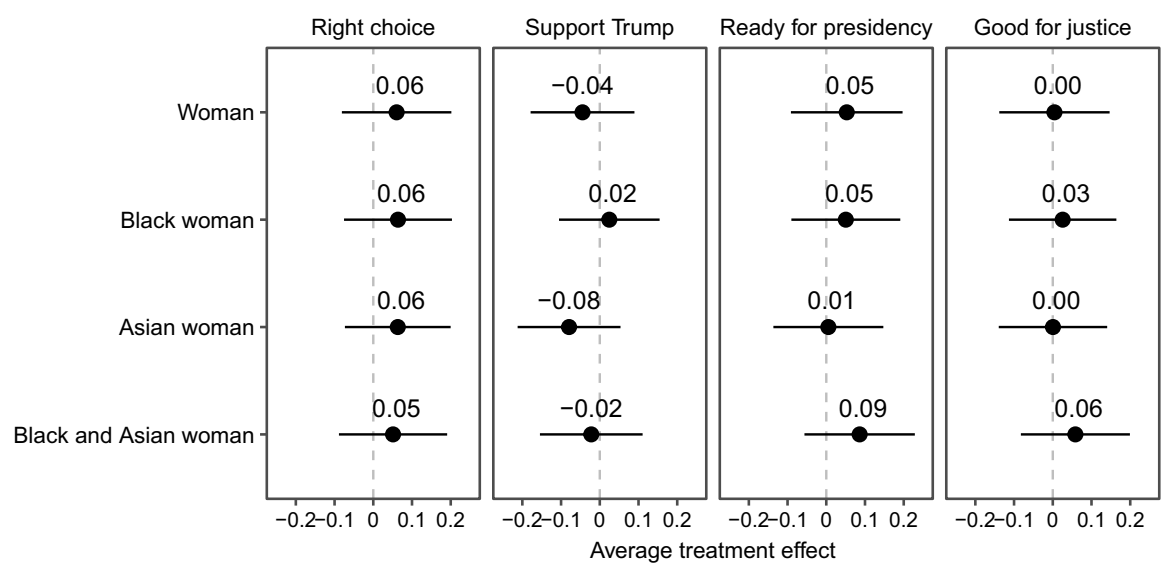

Figure 1.

Average treatment effects (post-nomination study) Note: The horizontal lines represent 95\% confidence intervals. Respondents in the control group were exposed to no identity-based frames.

treatment conditions, participants were presented with a news article excerpt about Harris's nomination that described her as a woman, a Black woman, an Asian woman, or a Black and Asian woman. Participants in the control condition saw an excerpt that omitted references to Harris's race and gender altogether.

After reading the text, participants were asked whether Harris was the right choice for Biden's running mate (Right choice); whether they support President Trump (Support Trump); whether Harris would be ready to serve as president if it became necessary (Ready for president); and whether Biden choosing Harris will help advance racial justice in the United States (Good for justice), all on five-point Likert scales. The first three questions capture some of the most important public attitudes related to Biden's selection of Harris as a running mate, while the fourth captures the extent to which the public agrees or disagrees with a common media narrative that links Harris to issues surrounding racial discrimination and the criminal justice system.

To estimate the average treatment effects, we run ordinary least squares (OLS) regression using each outcome question with numerical values assigned as an outcome variable and a set of four dichotomous variables for the randomly assigned groups as treatment variables. We use the control group as the baseline and add fifteen block dummy variables for block randomization to improve efficiency.

\section{Results}

Our main results for the post-nomination study are presented in Figure $16^{6}$ The dots and horizontal bars are point estimates for the average treatment effects and their

\footnotetext{
${ }^{6} \mathrm{We}$ also examine conditional treatment effects across party lines, racial groups, and gender and find few systematic patterns. These results are presented in Section D in the Supplementary Materials for both the post-nomination and post-inauguration studies, with results broken down into all possible strata. We also present treatment effect heterogeneity results using each of these three variables separately.
} 
95\% confidence intervals. None of the estimates are statistically significant at the 0.05 level. Furthermore, the effect sizes are consistently very small; the substantive magnitude of the estimated effects (in absolute terms) varies from only $0.03 \%$ to $5.92 \%$ of the standard deviations of the outcome variables among participants in the control group. Compared to the headline that ignores race and gender altogether, none of the other headlines change voters' attitudes toward Biden's choice, toward Trump, toward Harris's ability to lead, or toward their belief that her candidacy will advance racial justice.

\section{Post-inauguration study}

Are these null results driven by issues related to temporal validity (i.e. the context in which we ran the survey; see Munger 2019), construct validity (i.e. the bundling of the gender and race treatment in our initial study), or external validity (i.e. sample quality concerns)? To examine this question, we ran another experiment soon after Harris was inaugurated as vice president. We fielded this post-inauguration study on January 29-30, 2021, and collected a sample of 3,931 voters in the U.S. using Prolific. The post-inauguration survey was similar to the post-nomination survey but different in three important ways.

First, we increased the number of treatment conditions from four to seven. Specifically, we included article headlines and blurbs describing Harris as a woman, a Black woman, an Asian woman, a Black and Asian woman, a Black person, an Asian person, or a Black and Asian person. Respondents in the control group read an article excerpt that mentioned neither Harris's gender nor her racial identity. This fully crossed $2 \times 4$ factorial experiment (including a control condition) allows us to isolate the effect of the race cue from the effect of the gender cue more clearly. ${ }^{7}$ It also helps us understand how the two cues interact. Given the gender cue in our modified design, we also added a question about whether respondents think that having Harris as vice president will help advance gender equality in the U.S. (Good for equality), in addition to the question about racial justice, which appeared in both studies.

Second, we used a headline about Harris being inaugurated rather than one about Biden selecting her as his running mate, which allowed us to test the effect of treatment materials solely about Harris ("Kamala Harris becomes VP") rather than materials that also discuss an action taken by Biden ("Joe Biden picks Kamala Harris"). Indeed, the null result in the post-nomination study may have been driven at least in part by the reference to Biden's choice - a possibility we expand upon in the discussion.

Third, we recruited respondents using Prolific rather than Lucid. We also screened out those who failed attention check questions prior to treatment assignment to ensure a high-quality sample. These alternative choices for our survey

\footnotetext{
${ }^{7}$ Our first experiment did not provide respondents with a race cue with no mention of gender, but this was not an oversight. Our initial objective was to examine the influence of race-based cues, and we included a gender cue because most news coverage of Harris references her gender either explicitly or implicitly (through the use of pronouns), regardless of whether it cues race. In theory, however, the fully crossed design is better suited to isolate the effects of two different types of identity frames.
} 


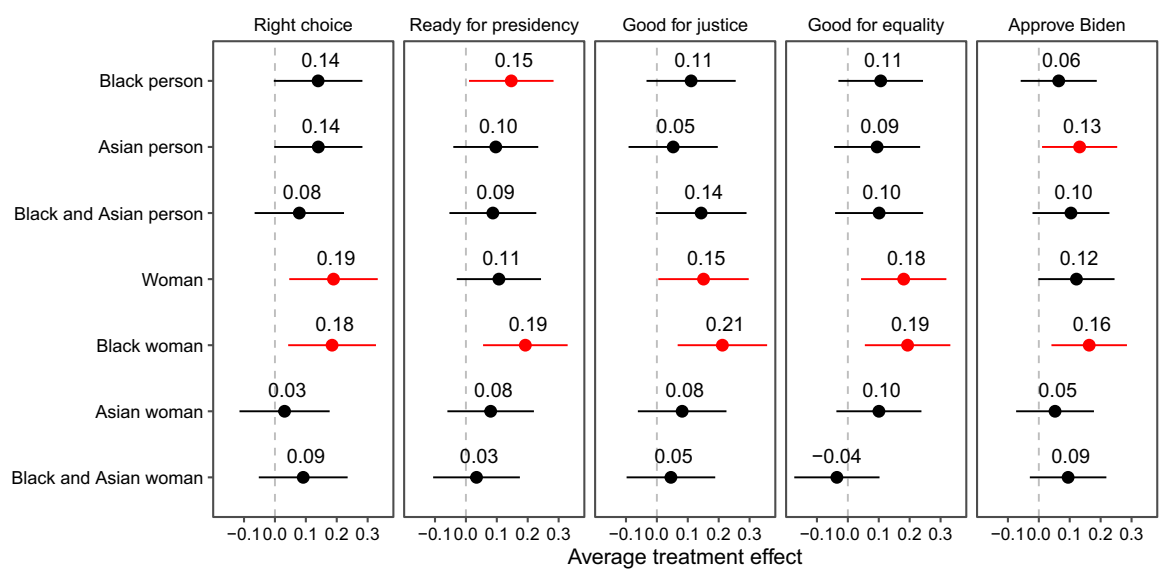

Figure 2.

Average treatment effects (post-inauguration study) Note: The horizontal lines represent $95 \%$ confidence intervals. Respondents in the control group were exposed to no identity-based frames. The effects that are significant at the 0.05 level are highlighted in red.

design are inspired by recent work about the potentially deteriorating quality of Lucid samples (Peyton, Huber, and Coppock 2021).

Aside from these differences, we followed the same procedures as in the postnomination study. We assigned respondents to treatment conditions within blocks generated based on the same set of demographic questions. All analyses again use the condition with no references to race or gender as the baseline category, and the statistical models are also the same.

\section{Results}

The results for the post-inauguration study are presented in Figure 2. Unlike in the post-nomination study, we see an interesting pattern of significant effects. Most notably, exposure to the Black woman cue (as compared to the control condition) increases agreement with the statement that Harris was the right choice for vice president; that she would be ready to assume the presidency; and that her role as vice president would help advance racial justice and gender equality by between 0.18 and 0.21 points on a five-point scale, with all estimates significant at the 0.05 level. This treatment also increases approval of Biden by 0.16 points. The effect sizes for the Black woman cue are considerably larger than those in the post-nomination study: the substantive magnitude of the estimated effects (in absolute terms) varies from $12.02 \%$ to $15.28 \%$ of the standard deviations of the outcome variables among participants in the control group. Additionally, we see some evidence that the woman cue increases support for Harris across three of the five outcomes we tested (Harris as the right choice and her vice presidency advancing racial justice and gender equality).

We see a handful of significant results for the Black person cue and the Asian person cue (without a reference to gender), although these effects reveal no 
systematic patterns. We consider them to be significant results due to random chance. Finally, we see no significant effects for any other cues (i.e., Black and Asian person cue, Asian woman cue, and Black and Asian woman cue). It is worth noting that out of 20 coefficients measuring the effects of four "Asian" cues in the post-inauguration study (Asian person, Asian woman, Asian and Black person, Asian and Black woman) on the five outcomes, only one of them (5\% of the 20 coefficients) is statistically significant at the 0.05 level.

Why is there a significant finding on the Black woman cue but not on the Asian woman cue? One possibility is that attitudes toward Black people in America have improved recently (at least among Democrats, who are overrepresented in the postinauguration study), while attitudes toward Asians have gotten worse (across both parties). In fact, anti-Asian hate crimes were peaking in the U.S. partly as a result of Donald Trump and others calling the coronavirus the "China Virus" when the postinauguration study was conducted, suggesting that the Asian frame could have acted as a negative cue. However, neither of these patterns would explain why we saw effects when Harris was described as a "Black woman" but no significant effects for any other cues that mentioned the word "Black." Another explanation might be that Harris is described as a Black woman in popular media accounts more often than she is an Asian woman, so the Black woman cue could have resonated more with the image of Harris that voters already have in their minds. Again, however, we do not see a clear reason why this would produce changes in the attitudes toward Harris that we measure. Indeed, one can imagine that this prior coverage could actually be a pretreatment concern that attenuates the treatment effects.

Broadly, the results in the post-nomination study suggest that cues emphasizing a multiracial candidate's background as a woman or a Black woman may impact public opinion. However, the overall evidence for a systematic effect of gender- or racebased cues is relatively weak. ${ }^{8}$ Our results do not tell why some cues (e.g., Black woman) are significant while others (e.g., Asian woman) are not. Given these uncertainties, we believe that an important avenue for future research is to investigate how and when intersectionality plays a role in shaping attitudes toward political candidates.

\section{Discussion}

Across two survey experiments testing the effect of race and gender cues on various measures of public opinion about Kamala Harris, a prominent multiracial political figure, the results are mixed at best. In a study conducted after her nomination as Joe Biden's running mate, identity-based cues had no impact on public opinion about Harris. In a subsequent study conducted once Harris was inaugurated, however, cues emphasizing Harris's role as a Black woman or just as a woman boosted popular support for her and for Biden and increased confidence in her ability to advance gender equality and racial justice.

\footnotetext{
${ }^{8}$ This finding is not necessarily attributable to the subtle differences across the treatment materials. Manipulation checks administered at the end of the survey indicate that participants were manipulated in the way we expected (see Section D.2 in the Supplementary Materials).
} 
There are at least two broad reasons why we may have observed null, substantively trivial results in the post-nomination study and some significant, substantively meaningful effects in the post-inauguration study. The first concerns the content of the treatments. Indeed, the two experiments differ across important political contexts-nomination as Biden's running mate vs. Harris's own inauguration as vice president. It is possible that references to Biden or other political figures (particularly white male ones) attenuate the influence of identity-based cues. It is also possible that voters react differently to news about party nominations, an internal process, than inaugurations, which may be perceived as collective achievements that result from a popular vote. Future research should evaluate these possibilities.

The second is that the respondents we recruited from two separate online survey platforms might differ in important ways. The sample in the post-nomination study, recruited from Lucid Theorem, is nationally representative of the adult population in the U.S. based on respondent age, gender, ethnicity, and region. However, nearly $30 \%$ of our participants failed to correctly identify that Harris was Biden's running mate even after exposure to the treatments. ${ }^{9}$ By contrast, our sample in the postinauguration study was recruited from Prolific, and we only allowed respondents who passed two pretreatment attention check questions to participate. While it still contains a diverse group of individuals (see Table D.2 in the Supplementary Materials), this highly attentive sample (Adams, Li, and Liu 2020) is not representative of the U.S. population. In particular, Asians and Democrats are overrepresented in our post-inauguration study. ${ }^{10}$ It is unclear, though, what experimental results based only on highly attentive respondents-even using quota-based "representative" samples - tell us about the attitudes and behavior of the general population. This is an open and important question for experimental political scientists; given a tradeoff between the two, should we maximize attentiveness or representativeness?

Beyond revealing mixed results, our studies share limitations that should also be noted. First, Peyton, Huber, and Coppock (2021) show that there is some evidence of increased participant inattentiveness in online survey experiments conducted during the COVID pandemic, which may have explained some of our null results. Second, while our focus on Harris increases the realism and contemporary relevance of our study, this choice also has drawbacks. Namely, because Harris is such a prominent political figure, some respondents may have already been aware of her gender and racial identities, which would limit the effectiveness of our treatments. To evaluate this possibility, we fielded a separate survey from February 18 to March 5, 2021,

\footnotetext{
${ }^{9}$ Because excluding these participants from our analysis could induce post-treatment bias (Montgomery, Nyhan, and Torres 2018), we include them in our main results. However, an exploratory analysis that excludes them from our sample in the post-nomination study yields results that are substantively identical (see Figure D.16 in the Supplementary Materials).

${ }^{10}$ See Section D.2 in the Supplementary Materials for more information on the differences between our samples for the two studies. Democrats are overrepresented in our Prolific sample (for the post-inauguration study), which may seem to explain the pattern of significant findings we observe on the Black woman and woman frames in the post-inauguration study. However, our analysis of treatment effect heterogeneity across subgroups in our sample (also presented in Section D.2) does not suggest that Democratic preferences are driving our results. In fact, Figure D.13 suggests that Republicans-rather than Democrats-are more likely to support Harris when they are exposed to the treatments.
} 
on a representative sample of 1,548 participants recruited from Qualtrics Panels (see Section E of the Supplementary Materials for more details). While 1,360 participants (87.9\%) correctly identified that Harris is female, only 272 participants $(17.6 \%)$ chose both "Black or African American" and "Asian or Pacific Islander" for her racial identity. In total, 35.6\% said that she is just Black or African American, $4.4 \%$ said that she is just Asian or Pacific Islander, and $10.3 \%$ indicated that they did not know. In fact, nearly $10 \%$ reported that Harris is white, suggesting that baseline knowledge of her racial background was relatively low during and after our two experimental studies were conducted.

Finally, attitudes toward presidential candidates are generally stable for most partisans in the U.S. (Campbell et al. 1960), so it is possible that race and gender cues have larger effects on public opinion about candidates in lower salience elections, or in contexts outside of the U.S. Lucas (2017), for instance, finds that media visibility for female and black representatives in the House has increased due to the media's interest in connecting their gender and racial identities to evaluations of candidates like Hillary Clinton, Sarah Palin, and Barack Obama. A promising direction for future research would be to systematically investigate these trends.

More generally, the results from our two experiments and some of the possible extensions discussed above suggest that framing effects may be conditional on, and susceptible to, social, political, and historical contexts. While our experimental studies differed in several ways, we can imagine many more differences that might exist across studies in this literature, given researcher degrees of freedom. If our results are sensitive to subtle changes in temporal context, construct validity, and sampling, we wonder about the extent to which other findings might be more sensitive to larger changes. Viewed in that light, we think that the field needs to replicate and extend existing scholarship on identity frames to evaluate what contexts could boost or attenuate the effects of identity-based cues. Research that accomplishes this goal will advance our understanding of the extent to which identity can act as a political advantage or disadvantage for multiracial politicians.

Supplementary material. To view supplementary material for this article, please visit https://doi.org/10. 1017/XPS.2021.33

Data Availability. The data, code, and any additional materials required to replicate all analyses in this article are available at the Journal of Experimental Political Science Dataverse within the Harvard Dataverse Network, at: https://doi.org/10.7910/DVN/UFXGOL (Clayton, Crabtree, and Horiuchi 2021).

Conflicts of Interest. The authors declare no conflicts of interest.

Ethics Statement. The post-nomiation and post-inauguration studies were approved by the Committee for the Protection of Human Subjects at Dartmouth College (ID: STUDY00032142, MOD00010609). The supplementary survey was also approved by the same committee (ID: STUDY00031862, MOD00010605, MOD00010641). This research adheres to APSA's Principles and Guidance for Human Subjects Research. No deception was used. Participants provided informed consent before participating in our experiments, were debriefed at the conclusion of each survey, and were compensated at minimum wage for their participation. 


\section{References}

Adams, Troy L., Yuanxia Li and Hao Liu. 2020. “A Replication of Beyond the Turk: Alternative Platforms for Crowdsourcing Behavioral Research-Sometimes Preferable to Student Groups." AIS Transactions on Replication Research 6. Article 15. https://aisel.aisnet.org/trr/vol6/iss1/15.

Adida, Claire L., Lauren D. Davenport and Gwyneth McClendon. 2016. "Ethnic Cueing Across Minorities: A Survey Experiment on Candidate Evaluation in the United States." Public Opinion Quarterly 80(4): 815-836.

Andersen, David J. and Jane Junn. 2010. "Deracializing Obama: White Voters and the 2004 Illinois U.S. Senate Race." American Politics Research 38(3): 443-470.

Caliendo, Stephen M. and Charlton D. McIlwain. 2006. "Minority Candidates, Media Framing, and Racial Cues in the 2004 Election.” Harvard International Journal of Press/Politics 11(4): 45-69.

Camera, Lauren. 2021. "Kamala Harris Makes History as First Female Vice President." US News and World Report. https://www.usnews.com/news/elections/articles/2021-01-20/kamala-harris-becomes-first-femalevice-president (last accessed on February 18, 2021).

Campbell, Angus, Philip E. Converse, Warren E. Miller and Donald E. Stokes. 1960. The American Voter. Chicago: University of Chicago Press.

Chong, Dennis, and James N. Druckman. 2007. "Framing Theory." Annual Review of Political Science 10: $103-126$.

Clayton, Katherine, Charles Crabtree, and Yusaku Horiuchi. 2021. "Do Identity Frames Impact Support for Multiracial Candidates? The Case of Kamala Harris.” https:/doi.org/10.7910/DVN/UFXGOL, Harvard Dataverse.

Davenport, Lauren D. 2018. Politics Beyond Black and White: Biracial Identity and Attitudes in America. New York: Cambridge University Press.

Davenport, Lauren, Annie Franco and Shanto Iyengar. 2022. "Multiracial Identity and Political Preferences." The Journal of Politics, forthcoming.

Gay, Claudine and Katherine Tate. 1998. "Doubly Bound: The Impact of Gender and Race on the Politics of black Women.” Political Psychology 19(1): 169-184.

Gershon, Sarah Allen. 2013. "Media Coverage of Minority Congresswomen and Voter Evaluations." Political Research Quarterly 66(3): 702-714.

Hardy-Fanta, Carol, Pei-te Lien, Dianne Pinderhughes and Christine Marie Sierra. 2016. Contested Transformation: Race, Gender, and Political Leadership in 21st Century America. New York: Cambridge University Press.

Harris, Kamala. 2019. The Truths We Hold: An American Journey. New York: Penguin Press.

Harris-Lacewell, Melissa and Jane Junn. 2007. "Old Friends and New Alliances: How the 2004 Illinois Senate Race Complicates the Study of Race and Religion." Journal of Black Studies 38(1): 30-50.

Huddy, Leonie and Stanley Feldman. 2009. "On Assessing the Political Effects of Racial Prejudice." Annual Review of Political Science 12: 423-447.

Hughes, Melanie M. 2011. "Intersectionality, Quotas, and Minority Women's Political Representation Worldwide." American Political Science Review 105(3): 604-620.

Hutchings, Vincent L. and Ashley E. Jardina. 2009. "Experiments on Racial Priming in Political Campaigns.” Annual Review of Political Science 12: 397-402.

Kahn, Kim Fridkin. 1994. “The Distorted Mirror: Press Coverage of Women Candidates for Statewide Office." The Journal of Politics 56(1): 154-173.

Larson, Stephanie Greco. 2006. Media \& Minorities: The Politics of Race in News and Entertainment. Oxford, U.K.: Rowman \& Littlefield.

Lee, Jennifer and Frank D. Bean. 2004. “America's Changing Color Lines: Immigration, Race/Ethnicity, and Multiracial Identification." Annual Review of Sociology 30: 221-242.

Lemi, Danielle Casarez. 2021. "Do Voters Prefer Just Any Descriptive Representative? The Case of Multiracial Candidates.” Perspectives on Politics 19(4): 1061-1081.

Lucas, Jennifer C. 2017. "Gender and Race in Congressional National News Media Appearances in 2008." Politics \& Gender 13(4): 569-596.

Mendelberg, Tali. 2001. The Race Card: Campaign Strategy, Implicit Messages, and the Norm of Equality. Princeton: Princeton University Press. 
Montgomery, Jacob M., Brendan Nyhan and Michelle Torres. 2018. "How Conditioning on Posttreatment Variables Can Ruin Your Experiment and What to Do About It." American Journal of Political Science 62(3): 760-775.

Munger, Kevin. 2019. "The Limited Value of Non-Replicable Field Experiments in Contexts with Low Temporal Validity." Social Media + Society 5(3). https://doi.org/10.1177\%2F2056305119859294.

Nelson, Thomas E., Zoe M. Oxley and Rosalee A. Clawson. 1997. "Toward a Psychology of Framing Effects." Political Behavior 19(3): 221-246.

Peyton, Kyle, Gregory A. Huber and Alexander Coppock. 2021. "The Generalizability of Online Experiments Conducted During the COVID-19 Pandemic." Journal of Experimental Political Science, forthcoming.

Philpot, Tasha S. and Hanes Walton, Jr. 2007. "One of Our Own: Black Female Candidates and the Voters Who Support Them.” American Journal of Political Science 51(1): 49-62.

Reeves, Keith. 1997. Voting Hopes Or Fears?: White Voters, Black Candidates \& Racial Politics in America. New York: Oxford University Press.

Reston, Maeve and Stephen Collinson. 2020. "Kamala Harris Officially Becomes the First Black Woman to Be a Major Party's Vice Presidential Nominee.” CNN. August 20, 2020, available at https://www.cnn. com/2020/08/19/politics/democratic-convention-harris-obama-clinton/index.html (last accessed on February 18, 2021).

Terkildsen, Nayda and Frauke Schnell. 1997. "How Media Frames Move Public Opinion: An Analysis of the Women's Movement.” Political Research Quarterly 50(4): 879-900.

Tharoor, Ishaan. 2020. "Kamala Harris and the Rise of Indian-Origin Politicians in the West." The Washington Post. https:/www.washingtonpost.com/world/2020/08/14/kamala-harris-rise-indianorigin-politicians-west/ (last accessed on February 18, 2021).

Ward, Orlanda. 2016. “Seeing Double: Race, Gender, and Coverage of Minority Women's Campaigns for the U.S. House of Representatives." Politics \& Gender 12(2): 317-343.

Winter, Nicholas J. G. 2008. Dangerous Frames: How Ideas about Race and Gender Shape Public Opinion. Chicago: University of Chicago Press.

Cite this article: Clayton K, Crabtree C, and Horiuchi Y (2023). Do Identity Frames Impact Support for Multiracial Candidates? The Case of Kamala Harris. Journal of Experimental Political Science 10, 112-123. https://doi.org/10.1017/XPS.2021.33 